\title{
Intracellular Digestion of Horseradish Peroxidase by the Intestinal Cells of Teleost Larvae and Juveniles
}

\author{
Yoshirou WATANABE*
}

(Received July 6, 1981)

\begin{abstract}
The intracellular digestion of proteins by the rectal epithelium cells in larvae and juveniles of five teleost species was investigated using horseradish peroxidase (HRP) as a marker substance. The HRP injected into the intestinal lumen was ingested from the apical surface of the cells, and was transported to the supranuclear area and then accumulated in several large granules. The supranuclear granules then changed to a number of small granules decreasing their HRP activity. The HRP activity finally disappeared from the small granules.

The time required for complete digestion of HRP by the cells differed with species, 7 to 15 days in Oncorhynchus masou and 10 hours to one day in Hypomesus olidus. In H. olidus, stomachless larvae showed a higher ability of intracellular digestion than juveniles in which the gastric glands have already been developed.
\end{abstract}

The pinocytotic ingestion of protein molecules by the intestinal cells has been observed in larvae of many fishes ${ }^{1-5)}$ and in adults of some stomachless fishes. ${ }^{\theta-9}$ The common condition of these fishes is that they do not have the functional stomach and, consequently, have no ability to hydrolyze food proteins sufficiently in their guts.

It is well known that mammalian fetuses and newborns ingest protein macromolecules by the intestinal cells. RoDEWALD ${ }^{10)}$ observed nonselective uptake of proteins by the distal intestine cells in contrast to the selective transport of antibodies by the proximal intestine cells, and emphasized that the distal cells degrade ingested materials for nutrition. This view was supported by the presence of a highly developed lysosomal system in the distal cells. ${ }^{11)}$

Recent studies on the ascidian gut revealed that vacuolated cells similar to distal intestine cells of mammals exist in the epithelium of the stomach and the intestine. ${ }^{12-14)}$ These cells were found to ingest a marker protein and, perhaps, digest it intracellularly. ${ }^{15,16)}$ The ingestion of proteins by the intestinal cells in fish should be a phenomenon homologous to the pinocytotic ingestion in ascidians and mammalian fetuses and newborns. The purpose of this study is to verify the intracellular digestion of proteins in the rectal epithelium cells of teleost larvae and juveniles, using horseradish peroxidase (HRP) as a marker protein.

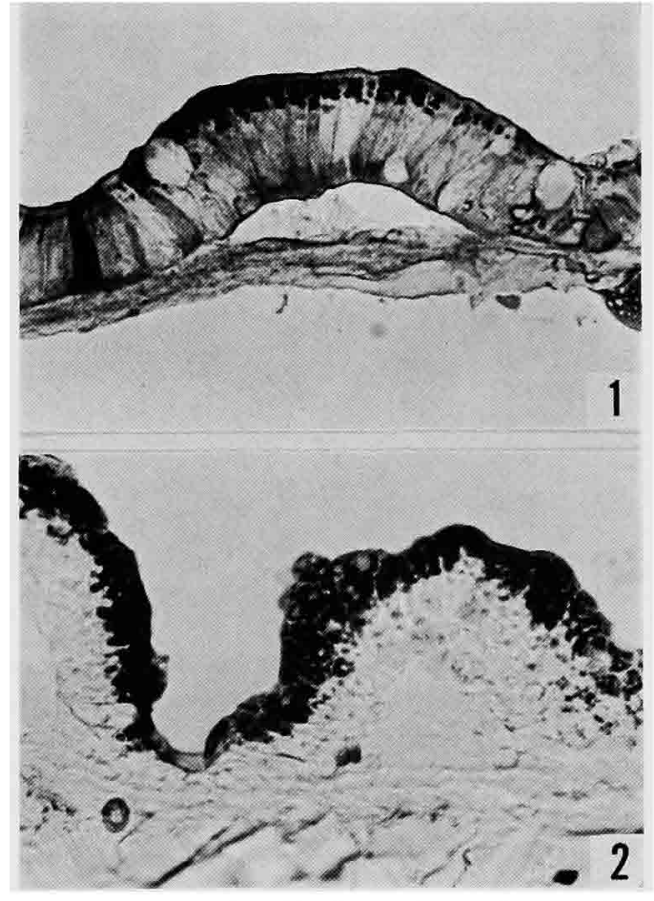

Figs. 1, 2. Rectal epithelium thirty minutes after injection of HRP. Fig. 1. Oncorhynchus masou (27.8 mm TL). Fig. 2. Cottus nozawae (11.2 $\mathrm{mm} \mathrm{TL}$ ). The HRP activity was detected as small dark brown granules at the apices of the epithelium cells. $(\times 400)$

* Laboratory of Physiology and Ecology, Faculty of Fisheries, Hokkaido University, Hakodate 041 (渡辺良朗: 北海道大学水産学部生理学生態学講座). 

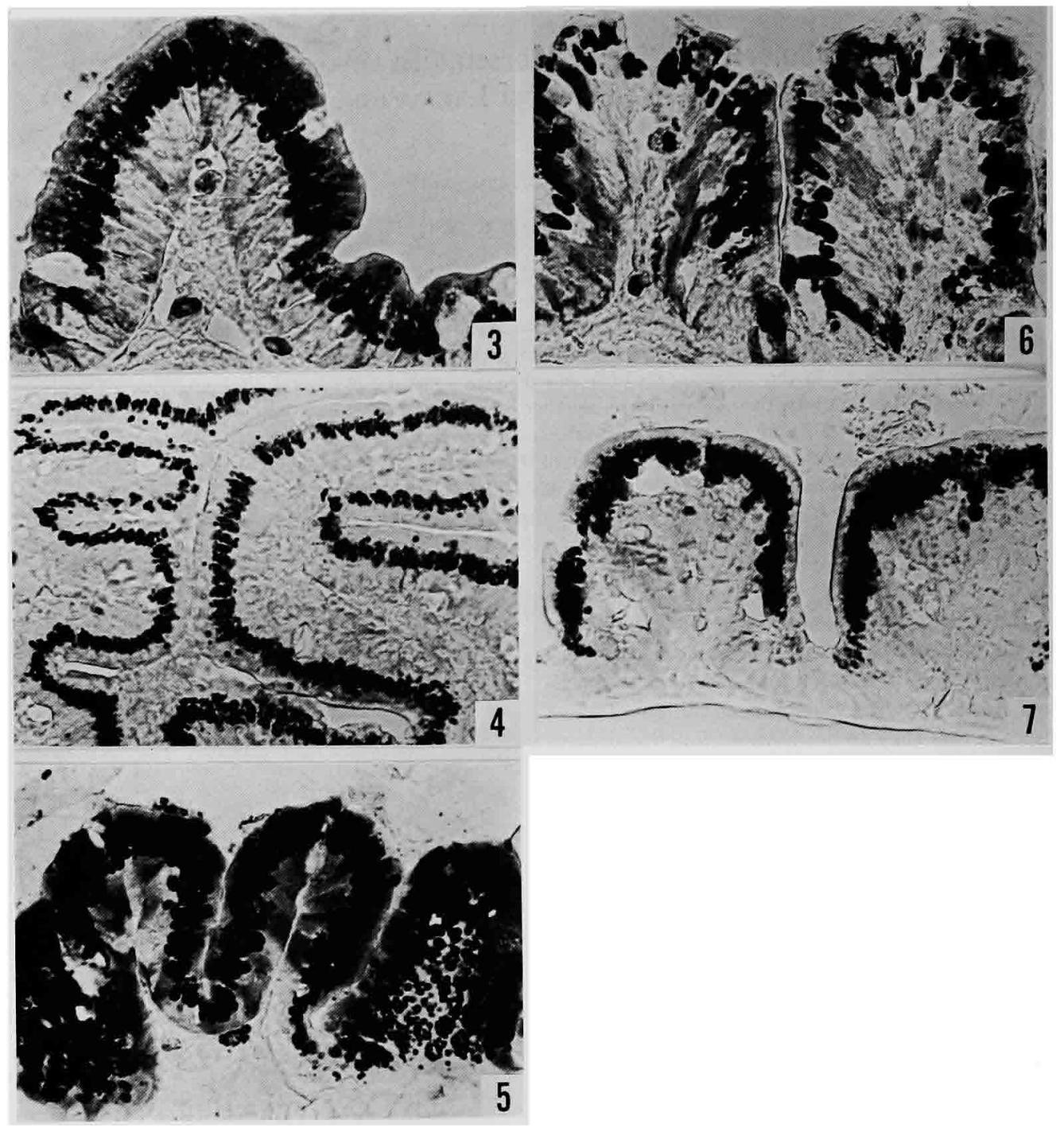

Figs. 3-7. Accumulation of HRP in large and dense granules in the supranuclear area of the rectal cells. Fig. 3. O. masou (30.4 mm TL), 7 days after injection. Fig. 4. Hypomesus olidus (21.4 mm TL), 90 minutes after injection. Fig. 5. C. nozawae (12.1 mm TL), 1 day after injection. Fig. 6. Tilapia nilotica $(12.5 \mathrm{~mm} \mathrm{TL}), 60$ minutes after injection. Fig. 7. Carassius auratus $(10.1 \mathrm{~mm}$ TL), 90 minutes after injection. $(\times 400)$

\section{Materials and Methods}

Larvae and juveniles of five teleost species, $\mathrm{On}$ corhynchus masou (27-31 mm TL), Hypomesus olidus (8.5-36.5 mm TL), Cottus nozawae (11-13 $\mathrm{mm}$ TL), Tilapia nilotica (10-12.5 mm TL), and Carassius auratus $(7.0-11 \mathrm{~mm}$ TL) were obtained by rearing larvae hatched newly in the laboratory under temperatures $9-10^{\circ} \mathrm{C}, 19-22^{\circ} \mathrm{C}, 13-15^{\circ} \mathrm{C}$, $25-27^{\circ} \mathrm{C}$, and $19-22^{\circ} \mathrm{C}$, respectively. Each fish was injected with $0.5 \%$ horseradish peroxidase (HRP) in physiological saline into the gut through a glass capillary. Histochemical detection of HRP followed GraHAM and KARNOVSKY. ${ }^{17)}$ A larva was fixed for 4 hours in cold $5 \%$ glutaraldehyde in $0.1 \mathrm{M}$ phosphate buffer ( $\mathrm{pH} 7.6$ ) at appropriate intervals after injection. After washed with the buffer containing $5 \%$ sucrose, the whole body or a 


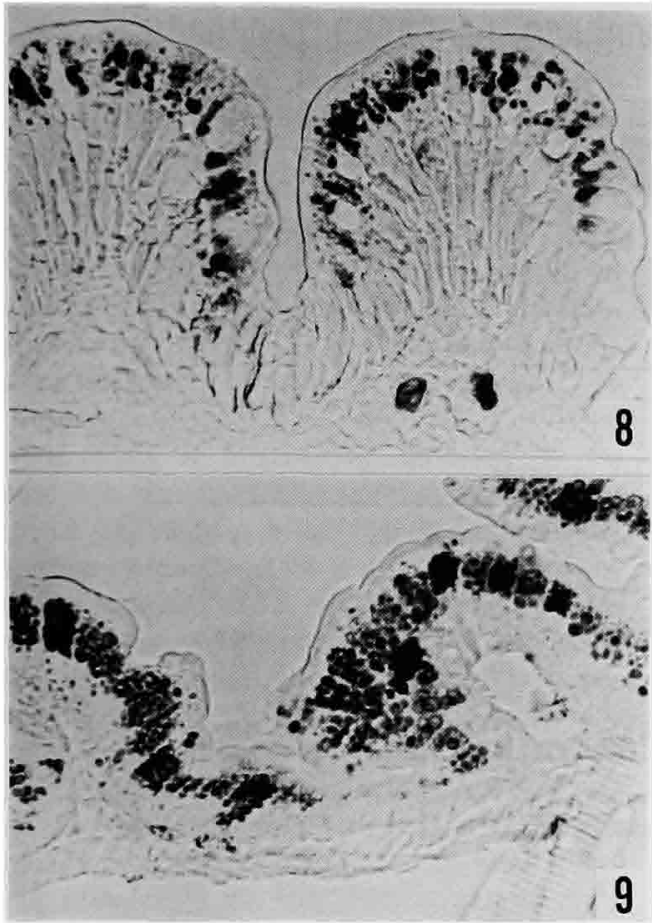

Figs. 8, 9. Small granules of weak HRP activities scattered in the supranuclear area. Fig. 8. O. masou (29.4 mm TL), 11 days after injection. Fig. 9. C. nozawae $(12.0 \mathrm{~mm} \mathrm{TL}), 3$ days after injection. A variety of densities of the granules among the cells in $C$. nozawae indicates different degrees of digestion. $(\times 400)$

dissected piece of the intestine was frozen, cut, and incubated in a solution of $0.05 \%$ diaminobenzidine tetrahydrochloride (DAB) and $0.01 \% \mathrm{H}_{2} \mathrm{O}_{2}$ in tris- $\mathrm{HCl}$ buffer ( $\mathrm{pH}$ 7.6). The HRP activity was observed as dark brown deposits under a light microscope.

\section{Results}

The rectal epithelium cells of larvae and juveniles of all five teleosts ingested and digested HRP intracellularly. The process from the ingestion to the complete digestion was virtually the same in the five species. Ingestion of HRP took place soon after the injection of HRP in the gut. Small dark brown granules of ingested HRP appeared first in the apical region of the cells (Figs. 1, 2). Following the ingestion, the HRP granules moved towards the nucleus progressively increasing their diameter. They were then accumulated in the
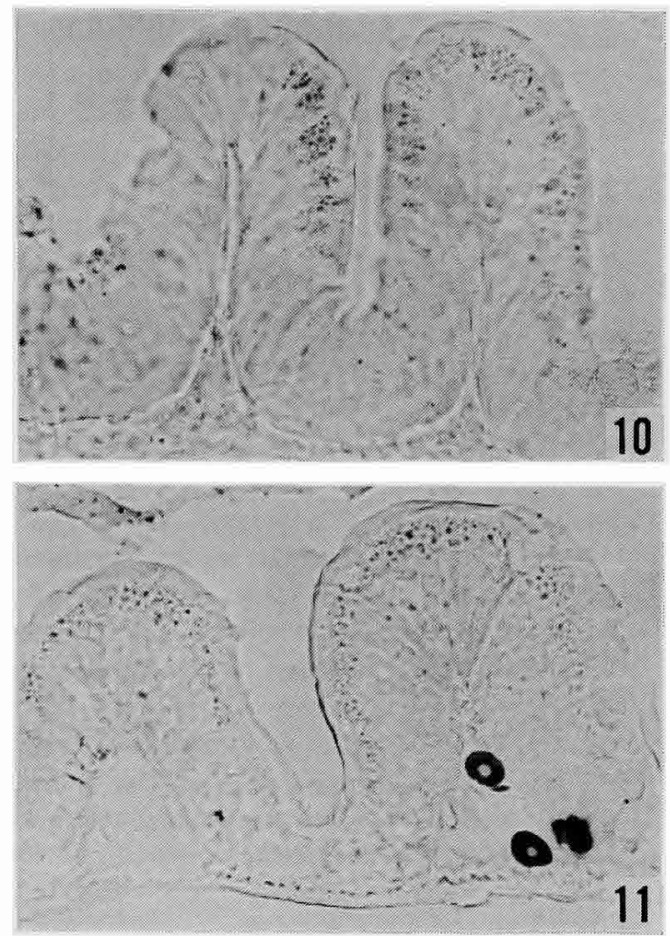

Figs. 10, 11. Disappearance of HRP activity in the supranuclear small granules. Fig. 10. $\mathrm{H}$. olidus (15.3 mm TL), 10 hours after injection. Fig. 11. C. nozawae (13.0 mm TL), 7 days after injection. $(\times 400)$

supranuclear area forming several large and dense granules (Figs. 3-7). The time required to reach this stage after injection was up to 7 days in $O$. masou, 5 hours in $H$. olidus, 1 day in $C$. nozawae, 5 hours in $T$. nilotica, and 10 hours in $C$. auratus. The diameter of the granules was about 3-5 $\mu \mathrm{m}$ in $O$. masou, $C$. nozawae, $T$. nilotica, and $C$. auratus, and $1-3 \mu \mathrm{m}$ in $H$. olidus. The large supranuclear granules then diminished their sizes and densities (Figs. 8, 9). Finally, the HRP activity disappeared leaving small vesicles of negative reaction in the supranuclear area (Figs. 10, 11). The time required for complete digestion differed largely with species; less than one day in $H$. olidus, one to four days in $T$. nilotica and $C$. auratus, and one or two weeks in $C$. nozawae and O. masou.

The process of complete digestion of HRP by the rectal epithelium cells is divided into 5 successive stages: ingestion of HRP into apical small granules (ingestion), transport of granules to the 


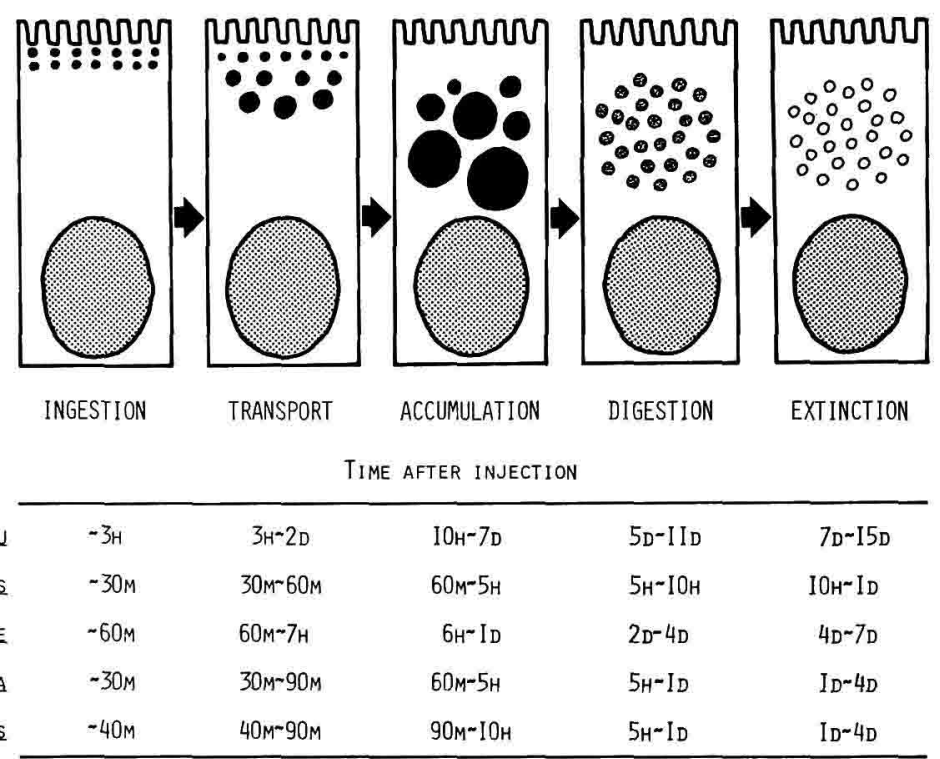

Fig. 12. Diagrammatic illustration of 5 successive stages of intracellular HRP digestion in the rectal cells and the time required to come to each stage after injection of HRP in larvae and juveniles of five species.

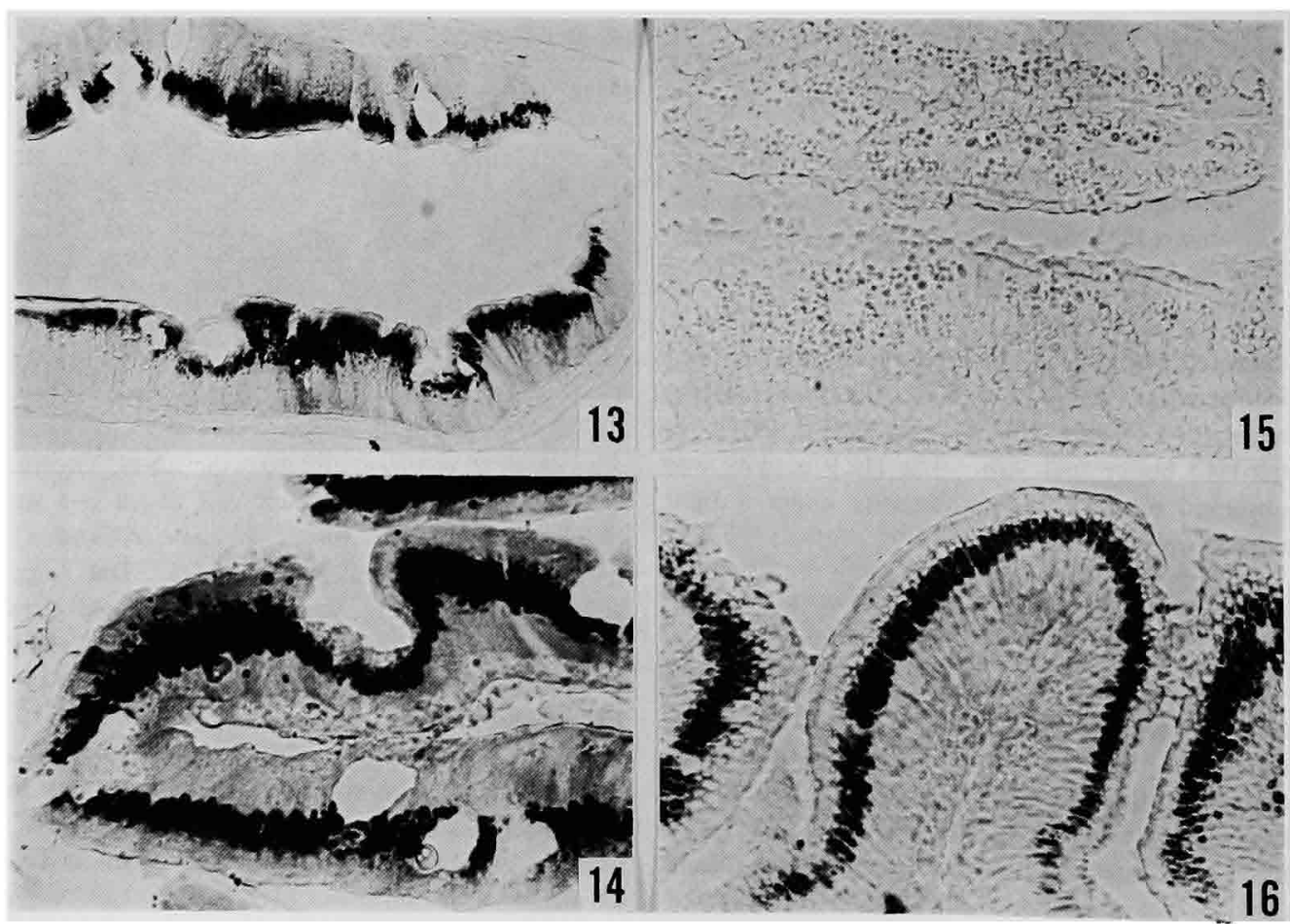

Figs. 13-16. Comparison of the ability of intracellular digestion of the rectum cells between larvae and juveniles of $\mathrm{H}$. olidus. Fig. 13. larva $(8.6 \mathrm{~mm} \mathrm{TL}), 90$ minutes after injection. $(\times 270)$ Fig. 14. juveniles (35.5 mm TL), 90 minutes after injection. $(\times 400)$ Fig. 15. larva $(8.9 \mathrm{~mm} \mathrm{TL})$, 1 day after injection. $(\times 400)$ Fig. 16. juvenile $(36.5 \mathrm{~mm} \mathrm{TL}), 1$ day after injection. $(\times 400)$ 
supranuclear area (transport), accumulation of HRP as large and dense granules in the supranuclear area (accumulation), digestion of HRP granules (digestion), and disappearance of HRP in the cell (extinction). A diagrammatic illustration of the five stages and the time required to come to each stage in five species are shown in Fig. 12. The ingested HRP was processed most rapidly in larvae of $H$. olidus and the digestion was completed in one day. In $O$. masou, the process up to the final stage required the longest time, 7 to 15 days.

The ability of intracellular digestion by the rectal cells was compared between larvae (8.5$9.0 \mathrm{~mm}$ TL) and juveniles (35.5-36.5 mm TL) of $H$. olidus by examining the distributions and activities of ingested HRP 90 minutes and one day after injection. At 90 minutes, both the larvae (Fig. 13) and the juveniles (Fig. 14) had large and dense granules in the supranuclear area, showing that the ingested HRP was in the stage of accumulation. One day after injection, no HRP activity was detected in the epithelium of larvae (Fig. 15), whereas in juveniles, small granules were apparently observed in the supranuclear area showing the stage of early digestion (Fig. 16). Thus, the larval epithelium cells apparently digested HRP more rapidly than those of juveniles.

\section{Discussion}

The process of intracellular digestion of HRP was essentially the same in larvae and juveniles of five species and was classified into five stages based on the distribution and activity of HRP in the rectal cells. The ingested HRP was transported to the supranuclear area and accumulated there as large and dense granules. On the basis of ultrastructural observations of the vacuolated cells in the ascidian gut, BurIGHeL ${ }^{10\rangle}$ assumed that ingested HRP was processed intracellularly through the following successive steps: pinocytotic invaginations, microvesicles, macrovesicles or vacuoles, and large supranuclear vacuoles. This process of intracellular transport of HRP in the ascidian gut is quite similar to that observed in the rectum of fish larvae.

The intracellular digestion of HRP was found to take place in small granules following the accumulation in the supranuclear area. IWAI ${ }^{2)}$ observed the occurrence of lysosomes in association with the appearance of some vacuoles in the posterior intestine cells of larval and juvenile carp which were fed on a mixed paste of corn oil and casein. GaUthiER and LANDIs ${ }^{\theta)}$ showed an intensive activity of acid phosphatase in the supranuclear area of the posterior intestine cells in adult goldfish.

The time required for complete digestion of HRP in the rectal cells differed with species. The rearing temperature must be a factor which affects the digestion time through the metabolic activity of the cells. Cold water species such as $O$. masou and $C$. nozawae needed a longer time than warm water species, $T$. nilotica. However, larvae of $H$. olidus reared at about $20^{\circ} \mathrm{C}$ digested ingested HRP faster than $T$. nilotica reared at about $26^{\circ} \mathrm{C}$. This shows that the digestion time is not necessarily determined by the rearing temperature.

In larvae of $H$. olidus, the ingestion and intracelJular digestion of food proteins by the rectal cells are undoubtedly an important means of nourishment, because their gastric glands have not yet differentiated and food proteins cannot be hydrolyzed in the stomach. The juveniles, on the other hand, have well developed gastric glands and are able to hydrolyze food proteins extracellularly. Comparing the intracellular appearances of ingested HRP one day after injection, the digestion in larvae is complete in contrast to the early digestion stage in juveniles. The higher ability of intracellular digestion in larvae may represent the importance of this function for nourishment.

Lower abilities of intracellular digestion in $O$. masou and $C$. nozawae judged from the time required for the completion of HRP digestion would be a reflection of little significance of this function for nourishment in addition to the effect of low temperatures. These fishes have well developed gastric glands at the stage of initiation of feeding. It may be concluded that fish larvae devoid of gastric glands at the early stage of feeding have difficulty digesting food proteins in their stomachs, and, therefore, ingestion and digestion of proteins by the rectal cells must be essential for their survival and growth.

\section{Acknowledgment}

The author thanks Professor J. Yamada of the Faculty of Fisheries, Hokkaido University, for his suggestion in pursuing this study and preparing the manuscript. 


\section{References}

1) T. Iwal: Z. Zellforsch., 91, 366-379 (1968).

2) T. IWAI: Arch. histol. jap., 30, 183-199 (1969).

3) T. IwaI and M. Tanaka: Bull. Japan. Soc. Sci. Fish., 34, 44-48 (1968).

4) M. TANAKA: Japan. J. Ichthyol., 19, 172-180 (1972).

5) Y. Watanabe: Bull. Japan. Soc. Sci. Fish., 47, 1299-1307 (1981).

6) G. F. Gauthier and S. C. Landis: Anat. Rec., 172, 675-702 (1972).

7) J. Noaillac-Depeyre and N. Gas: $Z$, Zellforsch., 146, 525-541 (1973).

8) J. Noaillac-Depeyre and N. Gas: Tissue \& Cell, 8, 511-530 (1976).
9) H. W. J. Stroband, H. v. d. Meer, and L. P. M. TIMMERMANS: Histochemistry, 64, 235-249 (1979).

10) R. Rodewald: J, Cell Biol., 58, 189-211 (1973).

11) R. Cornell and H. A. Padykula: Am. J. Anat., 125, 291-316 (1969).

12) N. W. Thomas: J. mar. biol. Ass. U. K, , 50, 737746 (1970).

13) P. Burighel and C. Mrlanesi: Z. Zellforsch., 145, 541-555 (1973).

14) P. Burighel and C. Milanesi: Cell Tiss. Res, 182, 357-369 (1977).

15) M. C. THoRndyke: Cell Tiss. Res., 184, 539550 (1977).

16) P. Burighel: J. Exp. Zool., 207, 131-142 (1979).

17) R. C. Graham, Jr. and M. J. Karnovsky: $J$. Histochem. Cytochem., 14, 291-302 (1966). 